\title{
Fibromyalgia syndrome: the pharmacological treatment options
}

\section{Il trattamento farmacologico della sindrome fibromialgica}

\begin{abstract}
P. Sarzi-Puttini ${ }^{1}$, R. Torta ${ }^{2}$, F. Marinangeli ${ }^{3}$, G. Biasi ${ }^{4}$, M. Spath ${ }^{5}$, D. Buskila ${ }^{6}$, R.H. Gracely ${ }^{7}$, M.A. Giamberardino ${ }^{8}$, L. Bazzichi ${ }^{9}$, M. Cazzola ${ }^{10}$, M. Di Franco ${ }^{11}$, S. Stisi ${ }^{12}$, F. Salaffi ${ }^{13}$, R. Casale ${ }^{14}$, G. Leardini ${ }^{15}$, R. Gorla ${ }^{16}$, A. Marsico ${ }^{17}$, R. Carignola ${ }^{18}$, L. Altomonte ${ }^{19}$, F. Ceccherelli2 ${ }^{20}$, G. Cassisi ${ }^{21}$, G. Ariolii ${ }^{22}$, A. Alciati $^{23}$, F. Atzeni ${ }^{1}$ (Italian Fibromyalgia Network)

${ }^{1}$ Rheumatology Unit, L. Sacco University Hospital, Milan, Italy; ${ }^{2}$ Department of Neuroscience, University of Turin, A.S.O. San Giovanni Battista of Turin, Turin, Italy; ${ }^{3}$ Department of Anesthesiology and Pain Medicine, L'Aquila University, L'Aquila, Italy; ${ }^{4}$ Unit of Rheumatology, University of Siena, Siena, Italy; ${ }^{5}$ Friedrich-Baur-Institute, University of Munich, Munich, Germany; ${ }^{6}$ Department of Medicine H, Soroka Medical Center and Faculty of Health Sciences, Ben Gurion University, Beer Sheva, Israel; ${ }^{7}$ Department of Medicine, University of Michigan Health System, Ann Arbor, Michigan, USA; ${ }^{8}$ Ce.S.I. "G. D'Annunzio" Foundation, Department of Medicine and Science of Aging, "G. D'Annunzio", University of Chieti, Italy; ${ }^{9}$ Department of Internal Medicine, Division of Rheumatology, S. Chiara Hospital, University of Pisa, Italy; ${ }^{10}$ Unit of Rehabilitative Medicine "Hospital of Circolo", Saronno (VA), Italy; ${ }^{11}$ Chair of Rheumatology, University la Sapienza Rome, Rome, Italy; ${ }^{12}$ Rheumatology Unit, "G.Rummo" Hospital, Benevento, Italy; ${ }^{13}$ Department of Rheumatology, Polytechnic University of the Marche Region, Ancona, Italy; ${ }^{14}$ Department of Clinical Neurophysiology and Pain Rehabilitation Unit, Foundation Salvatore Maugeri, IRCCS, Scientific Institute of Montescano, Montescano (PV), Italy; ${ }^{15}$ Rheumatology Unit, SS Giovanni e Paolo Hospital, Venice, Italy; ${ }^{16}$ Rheumatology and Clinical Immunology, Spedali Civili and University of Brescia, Italy; ${ }^{17}$ Rheumatology Unit, Hospital of Taranto, Taranto, Italy; ${ }^{18}$ Department of Neuroscience, University of Turin, A.S.O.

San Giovanni Battista of Turin, Turin, Italy; ${ }^{19}$ UOC of Rheumatology Hospital S. Eugenio, Rome, Italy;

${ }^{20} \mathrm{IOV}$ (Veneto Cancer Institute), IRCCS, Department of Pharmacology and Anesthesiology, University of Padua, Italy; ${ }^{21}$ Rheumatology Branch, Specialist Outpatients' Department, Belluno, Italy; ${ }^{22}$ Division of Rehabilitative Medicine and Rheumatology, General Hospital of Pieve di Coriano (Mantua), Italy; ${ }^{23}$ Department of Psychiatry, L. Sacco University Hospital, Milan, Italy
\end{abstract}

$\overline{\text { Competing interests: none declared }}$

\section{RIASSUNTO}

Il trattamento farmacologico della sindrome fibromialgica (FM) si è gradualmente arricchito di nuove molecole; tuttavia, nessun farmaco da solo è in grado di controllare completamente la costellazione dei sintomi che caratterizzano tale sindrome. Attualmente non è possibile trarre conclusioni definitive sul migliore approccio farmacologico per trattare la FM, poiché i risultati degli studi clinici controllati presentano limitazioni metodologiche e vi è una consistente eterogeneità nelle strategie terapeutiche, che rendono gli studi di difficile confronto. Una varietà di trattamenti farmacologici, che comprendono antidepressivi, farmaci antiinfiammatori non steroidei (FANS), oppioidi, sedativi, rilassanti muscolari e anti-epilettici vengono utilizzati per trattare la FM con risultati contrastanti. In questa review, si parlerà principalmente dei farmaci che hanno mostrato i risultati clinici più significativi. La natura della FM suggerisce che un approccio terapeutico a più livelli, sia farmacologico che non farmacologico, sembra costituire attualmente la decisione terapeutica più appropriata.

Reumatismo, 2008; 60: Supplemento 1: 50-58

\section{INTRODUCTION}

Fis ibromyalgia (FM), also known as fibromyalgia syndrome (FMS), is a frequently observed systemic disorder characterized by widespread musculoskeletal pain $(1,2)$. Its prevalence in the general

Corresponding author:

Piercarlo Sarzi-Puttini, MD

Director of Rheumatology Unit

L. Sacco University Hospital, Milan, Italy

E-mail: sarzi@tiscali.it population is $1-3 \%$, and it is more common among females than males. The American College of Rheumatology (ACR) classification criteria defines it as widespread pain with patients endorsing at least 11 of 18 tender points as painful (3). Although its defining feature is chronic, widespread pain, FM patients may also have a number of other symptoms including sleep disturbance, fatigue, irritable bowel syndrome, headache and mood disorders (1).

Current evidence advocates a multifaceted program emphasizing patient education, medications for im- 
proving symptoms, and aggressive use of exercise and cognitive-behavioural approaches to retain or restore function (4-6). Physicians and patients should be educated about current theories regarding the underlying pathophysiologic mechanisms of FM, and then set realistic goals for all modalities of treatment.

However, it is not possible to draw definite conclusions concerning the best approach to managing FM because results of randomized clinical trials present methodological limitations, and therapeutic programs are consistently heterogeneous, which renders them difficult to compare $(7,8)$. However, a variety of pharmacological treatments, including analgesics, antidepressants, antiepileptics and many other drugs have been used to treat symptoms of FM with mixed results (8). In this review, we will discuss those drugs that have produced the most significant clinical results in treating FM patients.

\section{Analgesics}

The use of steroids and nonsteroidal anti-inflammatory drugs (NSAIDs) in FM has had disappointing outcomes $(1,8)$. NSAIDs, which are commonly used for arthritic conditions, may be less effective for FM because pain associated with FM is not caused by muscle or joint inflammation. There is no scientific evidence that NSAIDs are effective when used alone in FM patients, although they may be useful adjuncts for analgesia when combined with tricyclic medications (1); the combination of NSAIDs with benzodiazepines, however, gave inconsistent results $(1,7-9)$.

The central nervous system (CNS) mechanisms for the disorder, specifically, central sensitization, central disinhibition and a dysfunctional hypothalamic-pituitary-adrenal axis, could justify the relatively reduced efficacy of NSAIDs and opioids, the latter being more effective for "peripheral" pain (7). However, NSAIDs can be helpful in reducing pain that flares with excessive physical activity, tendinitis or bursitis; but they should be used only as needed to avoid side effects. $\mathrm{COX}_{2}$ inhibitors have much fewer side effects, but have less efficacy in pain.

Acetaminophen acts differently for FM patients; it has a degree of strength for FM and is safe for use over long periods (9). Wolfe et al. surveyed rheumatic disease patients about their preferences for NSAIDs versus acetaminophen in terms of efficacy and side effects (10). There was a considerable and statistically significant preference for
NSAIDs among patients; but the authors stress that if safety and costs are issues, then the recommendation of the American College of Rheumatology that acetaminophen be the first choice, primarily for mild pain, seems appropriate given the long duration of safe use (11).

The use of NSAIDs or acetaminophen, with or without opioids, is always justified when patients who already suffer from FM have other peripheral sources of pain (osteoarthritis, inflammatory arthritis, degenerative disk disease) (11).

Opioids are meant to improve function in FM patients who are impaired by pain, even though there is an open debate about their usefulness and safety as a "specific" medication for fibromyalgia patients (12-14).

Few clinical trials exist that address the use of opioids to treat persistent pain in FM patients, but those trials show that these drugs are helpful for relieving FM pain; moreover, opioids can help to reduce sleep disturbances, anxiety and depression and to increase mobility and enjoyment of life (13, 15).

Potential side effects tend to decline over time, and addiction has been disproven by the scientific literature.

Opioids that are available on the Italian market include codeine, tramadol, oxycodone, hydromorphon, morphine, buprenorphine and fentanyl.

Furlan et al. (15) conducted a meta-analysis of 41 randomized trials (6019 patients, $7 \%$ affected by FM) to evaluate the efficacy of opioids ranging in duration from 1-16 weeks. They found that opioids were more effective than placebo for both pain and functional outcomes; and strong opioids were significantly superior to naproxen and nortriptyline, but only for pain relief. Despite the relative brevity of the trials, more than $1 / 3$ of the participants abandoned treatment (15).

Tramadol, in particular, was beneficial for FM patients $(8,9,12-14)$. It is an atypical pain reliever that differs from other narcotics in its action on the central nervous system, specifically, on reuptake of serotonin and norepinephrine. Its most common side effects are drowsiness, dizziness, constipation and nausea, and it should not be given in combination with tricyclic antidepressants.

Tramadol, used alone or in combination with acetaminophen, is commonly prescribed for relief of fibromyalgia pain (16-18) in a dose of 200-300 $\mathrm{mg} / \mathrm{d}$. A small double-blind, placebo-controlled trial initially suggested that tramadol was effective and well-tolerated in patients with FM (16). 
A larger RCT $(n=69)$ reported decreased visual analogue pain scores, improved pain relief and decreased pain threshold after tramadol treatment. Another study compared a combination of $37.5 \mathrm{mg}$ tramadol/325 $\mathrm{mg}$ acetaminophen tablets with placebo in 315 patients with FM. Pain and physical functioning improved significantly in the tramadol/acetaminophen-treated subjects. The average dose of tramadol/acetaminophen was $4.0 \pm 1.8$ tablets per day with an attrition rate of $19 \%(\mathrm{n}=29)$ due to adverse events. The attrition rate in the placebo-treated subjects was $12 \%(n=18)$. This study suggested that the combination of tramadol/acetaminophen was effective in treating FM patients' pain without causing serious adverse events (17).

Bennett et al. (18) examined efficacy data to compare the impact of tramadol/acetaminophen versus placebo on quality of life; the authors concluded that moderate-to-severe fibromyalgia pain significantly impairs health-related quality of life (HRQOL) in placebo-treated patients.

A recent study has demonstrated that transdermal buprenorphine, a strong opioid, has beneficial effects on severe widespread pain (VAS $>6 / 10$ ), but it is less effective on other symptoms that are typical of the disease (19).

FM that is diagnosed according to the ACR criteria seems to include patients with different pain processing mechanisms. Screening for disorders that may initiate or exacerbate symptoms of FM is critical; if comorbid disorders are not identified early and treated appropriately, therapies that target FM, only, may be ineffective.

In fact, there is a subset of FM patients that do not respond to opioids, while other patients, who may have overlapping conditions such as diabetes, chronic myofascial pain, temporomandibular joint disorder, arthritis, degenerative disc disease and other diseases, may benefit quite significantly from opioids $(8,18)$.

Physicians should obtain a careful medical and psychological profile of the patient before prescribing opioids $(17,18)$. Therapy with these drugs should be initiated after an adequate trial of acetaminophen for nociceptive pain and of tricyclic antidepressants or anticonvulsants.

To obtain a synergistic effect on analgesia, some patients may be prescribed combinations of different pain relievers (multimodal analgesia) with different effects on pain pathways, but not for managing side effects. Patients should be asked to give informed consent for treatment; even though it is not necessary for legal purposes, it would help to educate patients and give them a sense of responsibility (18).

It is appropriate to increase doses of immediate-release opioids slowly until pain reduction is achieved and then switch patients to controlled-release opioids, considering that most patients with chronic, non-malignant pain can be managed with $<200-300 \mathrm{mg} / \mathrm{d}$ of morphine (or equivalent).

When opioids prove to be necessary, they must, of course, be used with extreme caution. Patients should be evaluated periodically for continuing pain relief, side effects and indications of dependence. They must be closely monitored, must agree to seek psychotherapy and must complete a signed agreement to communicate with a single prescribing physician and a single dispensing pharmacy.

As with any chronic pain syndromes, patients should be carefully selected for opioid therapy, and a plan for appropriate follow-up and monitoring for pain reduction, outcome improvement, side effects and misuse should be clearly outlined. The interdiction of all opioid medications is inappropriate because some patients cannot achieve a reasonable quality of life and daily functioning with any other treatment.

Harris, et al. (20) have tried to investigate the apparent insensitivity of FM patients to opioids. Using positron emission tomography (PET), they found that FM patients, compared to healthy, matched controls, had reduced $\mu$-opioid-receptor (MOR)-binding potential (BP) in the nucleus accumbens, the anterior cingulate and the amygdala. These areas of the brain are known to play a role in pain modulation (14).

These findings indicate altered endogenous opioid analgesic activity in FM and suggest a possible explanation for the reduced efficacy of exogenous opioids in this population.

\section{Antidepressants}

The treatment of pain requires a multimodal approach that has to consider not only somatic aspects (i.e., pain onset, location, quality, quantity, duration, aggravating and alleviating factors), but also emotional aspects (i.e., mood and anxiety), cognitive aspects (i.e., coping styles, beliefs about pain), and environmental aspects (i.e., social context and patients' relationships) $(1,2,8)$. The hypothesis that pain, anxiety, chronic stress and depression share common pathogenetic backgrounds which are represented by neurotransmitters and immune response is noteworthy. As such, depression must 
be considered as a systemic disease that is related not only to neurotransmission imbalance, but also to other neurotrophic, neurosteroidal, CNS hormonal modifications and diffuse, autonomic, immunologic, and metabolic somatic changes $(8,21)$. According to this hypothesis, antidepressants restore neurotransmitter levels and modulate receptor expression in the hypothalamus, which normalizes hyperactivity of the hypothalamic-pituitary-adrenal (HPA) axis $(18,1)$. An over-activation of the HPA axis is observed in depression and in chronic stress, both of which are frequently present in patients with long-term pain disorders. Conversely, the response to stress is considered to play a crucial role in the pathogenesis of several syndromes, such as FM, chronic fatigue syndrome and irritable bowel syndrome $(22,23)$. Similarly, autonomic system alterations, such as sympathetic overactivity, are present in both depression and FM (21). Finally, pro-inflammatory cytokines within the CNS play a role in the pathophysiology of mood disorders (and pain), and modulating these cytokines via chronic antidepressant treatment contribute to improve depression (and pain) (24).

Several studies reported high frequency of mood disorders in FM patients $(25,26)$ compared to controls (27). Short-term clinical studies have shown efficacy for antidepressants in the treatment of FM (28).

Abnormalities in central monoaminergic neurotransmission that are observed in depression might play a role in FM pathophysiology because dysfunction of 5-HT- and NE-mediated descending pain-inhibitory pathways is an important mechanism related to the pain experienced by FM patients. Antidepressants that increase 5-HT and NEmediated neurotransmission are commonly used to treat FM and other chronic pain conditions, particularly neuropathic pain. Inhibition of both the 5-HT and NE reuptake transporters using tricyclic anti- depressants (TCA) or SNRIs (serotonergic and noradrenergic reuptake inhibitors), seems more effective in treating pain, and FM, in general, than inhibition of either transporter alone using selective serotonergic (SSRIs) or noradrenergic (NARIs) reuptake inhibitors (29-31).

However, the efficacy of TCAs is counterbalanced by side effects $(32,33)$, while the better-tolerated SSRIs demonstrate less effectiveness in treating fibromyalgia (34-37).

Antidepressants acting both on NE and 5HT induce a contextual increase of the endogenous opioid system response that raises the pain threshold at the periacqueductal level and increases the gate control of nociception at the spinal cord level (38). Antidepressants usually produce a fast, direct analgesic effect (on opioid, enkephalinergic, substance P) that is independent of mood state; it first appears after a few hours and can be achieved with low doses.

After a longer period of 2-3 weeks, a more robust analgesic effect develops when antidepressants have a more profound influence on mood and anxiety, and the affective and cognitive components of pain become regulated. This effect can only be produced with full doses that are easier to achieve with the new generation of antidepressants, such as SSRIs and SNRIs $(39,40)$.

Concerning the use of antidepressants in fibromyalgia, Perrot and colleagues (41) identified forty-nine publications on the use of antidepressants to treat painful rheumatologic conditions (including 37 studies and 12 meta-analyses) that were considered valid and used to develop the following considerations: the analgesic effect is higher for TCAs than SSRIs; clear evidence concerning doseresponse does not exist; the onset of action occurs within a week; the route of administration is oral; and side effects are more prevalent in TCAs than SSRIs. Unfortunately, this review included studies

Table I - Summary of the controlled studies of dual reuptake inhibitors (SNRI).

\begin{tabular}{|lccccccc|}
\hline Authors & References & Drug & N. Pts & Weeks & Dose & Outc. & Results \\
\hline Arnold, 2004 & 43 & DUL vs PLA & 207 & 12 & 120 & FIQ & DUL $>$ PLA \\
Russell, 2008 & 44 & DUL vs PLA & 520 & 24 & $20-120$ & BPI & DUL > PLA \\
Vitton et al., 2005 & 45 & MIL vs PLA & 125 & 4 & 200 & PGI & MIL > PLA \\
Arnold, 2005 & 46 & DUL > PLA & 354 & 12 & $60-120$ & FIQ & DUL $>$ PLA \\
& & & & & & \\
\hline
\end{tabular}


from 1966 to 2003 and did not consider new antidepressants such as SNRIs that are less effective than TCAs but remarkably more tolerated, particularly in long-term treatment (42).

Antidepressants that act on both NE and 5HT, i.e., SNRIs (Serotonergic and Noradrenergic Reuptake Inhibitors), are venlafaxine, duloxetine and milnacipran (milnacipran is not marketed in Italy).

Only a few controlled studies are available to date; these are summarized in Table I (43-46). All of these controlled studies demonstrated a significant superiority of the SNRI over placebo, and reported few and mild side effects (more frequent nausea, dry mouth and constipation in the first two weeks of treatment) (47).

Cyclobenzaprine, a tricyclic muscle relaxant, has also proven to be moderately effective in FM patients at a dose of 10-40 mg/day (48). This has recently been confirmed by a meta-analysis of five randomised, placebo-controlled trials (49), which showed that patients treated with cyclobenzaprine were approximately three times as likely to report symptom improvement, but there was a high dropout rate and the duration of the studies was short (49).

In our experience treating cancer pain with antidepressants, we have found that the impact of antidepressants on emotion and cognition is quite interesting: after a month of treatment, especially when brief psychotherapy is also included, patients who have pain as well as maladaptive coping styles (such as despair or hopelessness) begin to adopt positive coping styles (such as fighting spirit). This change is obtained by improving mood and reshaping beliefs about pain, both of which are extremely important in malignant pain diseases (50). A final consideration involves the placebo effect in pain treatment.

In a medical model placebo is manly considered an inert substance, and at present, it is well known that the placebo effect on pain is mediated by an opioid mechanism (51).

In clinical practice, however, we consider that a placebo effect is also an adjunct response to an active drug: the individual expectation of a positive response will increase the pharmacological action of the drug, while a negative expectation will reduce the effectiveness of the therapy (nocebo effect).

The placebo effect is highly related to the relationship between patient and physician (52), a relationship that is also important in affecting pharmacological treatments as well.

\section{Anticonvulsants/antiepileptic drugs}

Antiepileptic drugs (i.e., gabapentin and pregabalin) act at a number of sites that may be relevant to pain. The precise mechanism of their analgesic effect remains unclear, but it is thought that they limit neuronal excitation and enhance inhibition (53). The relevant sites of action include voltagegated ion channels (i.e., sodium and calcium channels), ligand-gated ion channels, excitatory receptors for glutamate and Nmethyl-D-aspartate, the inhibitory receptors for gamma-aminobutyric acid (GABA) and glycine (54).

In preclinical pain models, gabapentin is a structural analogue of the neurotransmitter GABA; it exerts robust analgesic and anti-allodynic effects in syndromes that are secondary to sensitization of pain responses but has minimal effects in models of acute, transient pain (55). Taylor, et al. (56) suggested that gabapentin did not appear to reduce acute pain from injury, but appeared to be effective in reducing abnormal hypersensitivity (allodynia and hyperalgesia) induced by inflammatory responses or nerve injury. The antinociceptive effects of gabapentin are hypothesized to be mediated by modulation of calcium channels via ${ }_{2}$ binding, modulation of transmission of GABA, and possibly other additional unidentified mechanisms.

Arnold, et al. (57) conducted a 12-week, randomized, double-blind study that was designed to compare gabapentin $(1,200-2,400 \mathrm{mg} /$ day; $\mathrm{n}=75$ patients) versus placebo ( $\mathrm{n}=75$ patients) for efficacy and safety in treating pain associated with FM. Patients who were treated with gabapentin displayed significantly greater improvements in the Brief Pain Inventory (BPI) average pain interference score, the Fibromyalgia Impact Questionnaire (FIQ) total score, the Clinical Global Impression of Severity, the Patient Global Impression of Improvement, the Medical Outcomes Study (MOS) Sleep Problems Index, and the MOS Short Form 36 vitality score; but they did not show improvements in the mean tender point pain threshold or the Montgomery Asberg Depression Rating Scale. Gabapentin was generally well tolerated by these FM patients.

Pregabalin is an $\alpha_{2}-\delta$ ligand that has analgesic, anxiolytic-like, and anticonvulsant activity in animal models. Biochemical studies identified $\alpha_{2}-\delta$ (type 1 ) as the primary binding site for both pregabalin and the related compound, gabapentin (57). Al$\mathrm{pha}_{2}$-delta is an auxiliary protein associated with voltage-gated calcium channels. Potent binding of pregabalin at the $\alpha_{2}-\delta$ site reduces calcium influx 
at nerve terminals (58) and, therefore, reduces the release of several neurochemicals, including glutamate, noradrenaline, and substance P $(58,59)$. The reduced neurotransmitter release caused by drug binding at the $\alpha_{2}-\delta$ site is presumed to account for the the analgesic, anticonvulsant, and anxiolytic-like actions of pregabalin in animal models. Reduction of neurotransmitter release from neurons in the spinal cord and brain is also proposed as the mechanism of action that may result in clinical benefit for patients with FM. In an 8week, multicentre, double-blind, randomised, placebo-controlled clinical trial, Crofford, et al. (61) compared the effects of pregabalin $(150,300$ and $450 \mathrm{mg} /$ day) on pain, sleep, fatigue and healthrelated quality of life in $529 \mathrm{FM}$ patients, and found that it was superior to placebo in reducing the scores for pain, SF-MPQ, sleep index, fatigue, patient and clinician global impression of change, and four of the eight SF-36 domains. The most frequent adverse events were dizziness and somnolence.

Arnold, et al. (62) conducted a study to assess symptoms of anxiety and depression in a large cohort of FM patients to determine the impact of these symptoms on pain during a course of pregabalin treatment. The results indicated that anxiety symptoms were more common than depressive symptoms in this cohort, and that the pain treatment effect of pregabalin did not depend on baseline anxiety or depressive symptoms, which suggests that pregabalin improves pain in patients with or without these symptoms. Finally, much of the pain reduction appears to be independent of improvements in anxiety or mood symptoms.

In a multicenter, double-blind, placebo-controlled trial, Mease, et al. (63) randomly assigned 748 FM patients to receive placebo or pregabalin $(300,450$, or $600 \mathrm{mg} / \mathrm{day}$, dosed twice daily) for 13 weeks. The pregabalin groups showed statistically significant improvements in mean pain score and in $\mathrm{Pa}-$ tient Global Impression of Change (PGIC) compared to the placebo group. Improvements in FIQTotal Score for the pregabalin groups were numerically but not significantly greater than those for the placebo group. Compared with placebo, all pregabalin treatment groups showed statistically significant improvement in assessments of sleep and in patients' impressions of their global improvement. Dizziness and somnolence were the most frequently reported adverse events. The study concluded that pregabalin monotherapy provides clinically meaningful benefit to patients with FM.

\section{Other drugs}

Serotonergic receptors have been implicated in processing information and in the development of pain in FM, and randomised, controlled trials have found that tropisetron, a 5-hydroxytryptophan intermediate metabolite of L-tryptophan, is more effective than placebo $(64,65)$

In a pilot study, Papadopoulos, et al. (66) found that tropisetron might be effective in treating pain in FM patients, but Koeppe, et al. (67) did not observe any significant change in the intensity of habitual pain following local injection of tropisetron in FM patients who took part in a pre- and post-treatment, double-blind study of pain perception and central processing.

In an open trial of pindolol, a mixed serotonin (5HT)(1A) presynaptic autoreceptor/beta-adrenergic receptor antagonist, at a dose of $7.5 \mathrm{mg} /$ day (titrated to a maximum of $15 \mathrm{mg} /$ day) for a total of 90 days in 20 female FM patients, Wood, et al. (68) demonstrated a significant improvement in primary tender point counts $(\mathrm{p}<0.001)$, tender point scores $(\mathrm{p}<0.001)$, and FIQ $(\mathrm{p}<0.005)$. The depression and anxiety scores did not significantly change among the women who completed the study, and the impact on cardiovascular parameters was clinically insignificant (68).

Despite the suggestion of relative growth hormone (GH) deficiency in FM patients and reports of improvements after the administration of $\mathrm{GH}$ injections, the enthusiasm for this approach has been dampened by the appearance of adverse effects, the need for frequent injections, and its high cost (69).

Low doses of a $\beta$-blocker have been tried in selected cases with prominent autonomic symptoms, such as palpitations and orthostatic tachycardia; however, the effects are not known (68).

Lidocaine hydrochloride injections, botulinum toxin injections, are sometimes offered to patients with FM $(1,8,70,71)$.

\section{CONCLUSIONS}

The success of the current treatments for FM is still limited, and there is a need for the development of new drugs that are targeted at the CNS, and that undergo efficacy and toxicity testing in longterm, comparative trials involving large numbers of patients. Recent data concerning polymorphisms of the genes in the serotonergic and dopaminergic systems may facilitate the development of a more 
rational, genotype-based, pharmacological approach (72). Subjects with the short 5HTTLPR allele in the serotonergic system may be more suitable candidates for antidepressant treatment (73), whereas subjects with polymorphisms in the dopaminergic system, such as the dopamine D4 receptor exon III repeat polymorphism, may be candidates for dopaminergic medications (73). Certainly, further randomized, controlled clinical trials that are conducted with subgroups of patients using standardized outcome measurements and sufficient length of follow-up are necessary to observe and document changes in patient symptoms and behaviors over time.

\section{SUMMARY}

Pharmacological treatment has been gradually enriched by a variety of compounds; however, no single drug is capable of fully managing the constellation of fibromyalgia (FM) symptoms. Currently, it is not possible to draw definite conclusions concerning the best pharmacological approach to managing FM because results of randomized clinical trials present methodological limitations and therapeutic programs are too heterogeneous for adequate comparison. However, a variety of pharmacological treatments including antidepressants, nonsteroidal anti-inflammatory drugs (NSAIDS), opioids, sedatives, muscle relaxants and antiepileptics have been used to treat FM with varying results. In this review, we will evaluate those pharmacological therapies that have produced the most significant clinical results in treating FM patients.

The nature of FM suggests that an individualized, multimodal approach that includes both pharmacologic and nonpharmacologic therapies seems to be the most appropriate treatment strategy to date.

Key words - Pharmacologic approach, non-pharmacologic approach, opioids, antiepileptics, nonsteroidal anti-inflammatory drugs.

Parole chiave - Terapia farmacologica, terapia non-farmacologica, oppiodi, antiepilettici, anti-infiammatori non steroidei.

\section{REFERENCES}

1. Mease P. Fibromyalgia syndrome: review of clinical presentation, pathogenesis, outcome measures, and treatment. J. Rheumatol 2005; 75: 6-21.

2. Shmerling RH. A review of fibromyalgia. Am. J Manag Care 2004; 10: 794-800.

3. Wolfe F, Smythe HA, Yunus MD. The American College of Rheumatology 1990 Criteria for the Classification of Fibromyalgia. Report of the Multicenter Criteria Committee. Arthritis Rheum 1990; 33: 160-72.

4. Sim J, Adams N. Physical and other non-pharmacological interventions for fibromyalgia. Bailliere's Clin Rheumatol 1999; 13: 507-23.

5. Offenbaecher M, Stucki G. Physical therapy in the treatment of fibromyalgia. Scand J Rheumatol 2000; 29: 78-85.

6. Busch A, Schachter CL, Peloso PM, Bombardier C. Exercise for treating fibromyalgia syndrome. Cochrane Database Syst Rev 2002 (3): CD003786.

7. Keel PJ. Pain management strategies and team approach. Bailliere's Clin Rheumatol 1999; 13: 493-506.

8. Sarzi-Puttini P, Buskila D, Carrabba M, Doria A, Atzeni F. Treatment strategy in fibromyalgia syndrome: where are we now? Semin Arthritis Rheum 2008; 37 : 353-65.

9. Cazzola M, Sarzi-Puttini P, Buskila D, Atzeni F. Pharmacological treatment of fibromyalgia. Reumatismo. 2007; 59: 280-91.
10. Wolfe F, Zhao S, Lane N. Preference for nonsteroidal antiinflammatory drugs over acetaminophen by rheumatic disease patients: a survey of 1,799 patients with osteoarthritis, rheumatoid arthritis, and fibromyalgia. Arthritis Rheum. 2000; 43: 378-85.

11. Schnitzer TJ. Update on guidelines for the treatment of chronic musculoskeletal pain. Clin Rheumatol 2006; 25 (Suppl 1): S22-9.

12. Carville SF, Arendt-Nielsen S, Bliddal H, Blotman F, Branco JC, Buskila D, et al. EULAR. EULAR evidencebased recommendations for the management of fibromyalgia syndrome. Ann Rheum Dis. 2008; 67: 536-41.

13. Clauw DJ. Pharmacotherapy for patients with fibromyalgia. J Clin Psychiatry. 2008; 69 Suppl 2: 25-9.

14. No authors listed. Now we know: why opioids don't work against fibromyalgia pain. Recent study reveals reduced opioid receptor availability in the brain; but a new FDA-approved drug brings relief. Health News 2008; 14: 3 .

15. Furlan AD, Sandoval JA, Mailis-Gagnon A, Tunks E. Opioids for chronic noncancer pain: a meta-analysis of effectiveness and side effects. CMAJ 2006; 23, 174: 1589-94.

16. Biasi G, Manca S, Manganelli S, Marcolongo R. Tramadol in the fibromyalgia syndrome: a controlled clinical trial versus placebo. Int J Clin Pharmacol Res 1998; 18: 13-9.

17. Bennett RM, Kamin M, Karin R, Rosenthal N. Tramadol and acetaminophen combination tablets in the 
treatment of fibromyalgia pain. Am J Med 2003; 114: 537-45.

18. Bennett RM, Schein J, Kosinski MR, Hewitt DJ, Jordan DM, Rosenthal NR: Impact of fibromyalgia pain on health-related quality of life before and after treatment with tramadol/acetaminophen. Arthritis Rheum 2005; 53: 519-27.

19. Kress HG. Clinical update on the pharmacology, efficacy and safety of transdermal buprenorphine. Eur $\mathbf{J}$ Pain. 2008. [Epub ahead of print].

20. Harris JD. Management of expected and unexpected opioid-related side effects. Clin J Pain. 2008; 24: S8S13.

21. Sarzi-Puttini P, Atzeni F, Diana A, Doria A, Furlan R Increased Neural Sympathetic Activationin Fibromyalgia Syndrome Ann NY Acad Sci 2006; 1069: 109-117.

22. Gupta A, Silman AJ. Psychological stress and fibromyalgia: a review of the evidence suggesting a neuroendocrine link. Arthritis Res Ther 2004; 6: 98-106.

23. McBeth J, Chiu YH, Silman AJ, Ray D, Morriss R, Dickens C, Gupta A, Macfarlane GJ. Hypothalamic- pituitary-adrenal stress axis function and the relationship with chronic widespread pain and its antecedents. Arthritis Res Ther 2005; 7: 992-1000.

24. Torta R. Depression as Systemic Disease: the Antidepressants Spectrum of Action. Psycho-Oncology 2006; 15: 3-4.

25. Epstein SA, Kay G, Clauw D, Heaton R, Klein D, Krupp L, Kuck J, et al. Psychiatric disorders in patients with fibromyalgia. A multicenter investigation. Psychosomatics 1999; 40: 57-63.

26. Henningsen P, Zimmermann T, Sattel H. Medically unexplained physical symptoms, anxiety, and depression: a meta-analytic review. Psychosom Med 2003; 65: 52833.

27. Carta MG, Cardia C, Mannu F, Istilla G, Hardoy MC, Anedda $\mathrm{C}$, et al. The high frequency of manic symptoms in fibromyalgia does influence the choice of treatment? Clin Pract Epidem Ment Health 2006; 2: 36.

28. Goldenberg DL, Burckhardt C, Crofford L. Management of fibromyalgia syndrome. JAMA 2004; 292: 2388-95.

29. Goldenberg D, Mayskiy M, Mossey C, Ruthazer R, Schmid C. A randomized, double-blind crossover trial of fluoxetine and amitriptyline in the treatment of fibromyalgia. Arthritis Rheum 1996; 39: 1852-9.

30. Fishbain D. Evidence-based data on pain relief with antidepressants. Ann Med 2000; 32: 305-16.

31. Maizels M, McCarberg B. Antidepressants and antiepileptic drugs for chronic non-cancer pain. Am Fam Physician 2005; 71: 483-90.

32. Arnold LM, Keck PE Jr, Welge JA. Antidepressant treatment of fibromyalgia: a meta-analysis and review. Psychosomatics 2000; 41: 104-13.

33. O'Malley PG, Balden E, Tomkins G, Santoro J, Kroenke K, Jackson JL. Treatment of fibromyalgia with antidepressants: a meta-analysis. J Gen Intern Med 2000; 15: 659-66.

34. Wolfe F, Cathey MA, Hawley DJ. A double-blind placebo controlled trial of fluoxetine in fibromyalgia. Scand J Rheumatol 1994; 23: 255-9.

35. Norregaard J, Volkmann H, Danneskiold-Samsoe B. A randomized controlled trial of citalopram in the treatment of fibromyalgia. Pain 1995; 61: 445-9.

36. Anderberg UM, Marteinsdottir I, von Knorring L. Citalopram in patients with fibromyalgia: a randomized, double-blind, placebo-controlled study. Eur J Pain 2000; 4: 27-35.

37. Arnold LM, Hess EV, Hudson JI, Welge JA, Berno SE, Keck PE Jr. A randomized, placebo-controlled, doubleblind, flexible-dose study of fluoxetine in the treatment of women with fibromyalgia. Am J Med 2002; 112: 191-7.

38. Torta R, Lacerenza M. Depressione e Dolore, Utet, Milano 2002; 199.

39. Torta R, Berra C. La terapia neuropsicofarmacologica nel dolore. In: Torta R., Mussa A: PsicOncologia. Il modello biopsicosociale. Centro Scientifico Editore, Torino, 2007.

40. Arnold LM, Hess EV, Hudson JI, Welge JA, Berno SE, Keck PE Jr. A randomized, placebo-controlled, doubleblind, flexible-dose study of fluoxetine in the treatment of women with fibromyalgia. Am J Med 2002; 112: 191-7.

41. Perrot S, Maheu E, Javier RM, Eschalier A, Coutaux A, LeBars M, et al. Guidelines for the use of antidepressants in painful rheumatic conditions. Eur J Pain. 2006; 10: 185-92.

42. Sindrup SH, Otto M, Finnerup NB, Jensen TS. Antidepressants in the treatment of neuropathic pain. Basic Clin Pharmacol Toxicol 2005; 96: 399-409.

43. Arnold LM, Lu Y, Crofford LJ, Wohlreich M, Detke MJ, Iyengar S, Goldstein DJ. A double-blind, multicenter trial comparing duloxetine with placebo in the treatment of fibromyalgia patients with or without major depressive disorder. Arthritis Rheum 2004; 50: 2974-84.

44. Russell IJ, Mease PJ, Smith TR, Kajdasz DK, Wohlreich MM, Detke MJ, et al Efficacy and safety of duloxetine for treatment of fibromyalgia in patients with or without major depressive disorder: Results from a 6month, randomized, double-blind, placebo-controlled, fixed-dose trial. Pain 2008; 136: 432-44.

45. Vitton O, Gendreau M, Gendreau J, Kranzler J, Rao SG. A double-blind placebo-controlled trial of milnacipran in the treatment of fibromyalgia. Hum Psychopharmacol Clin Exp 2004; 19: 27-35.

46. Arnold LM, Rosen A, Pritchett YL, D’Souza DN, Goldstein DJ, Iyengar S, Wernicke JF. A randomized, double-blind, placebo-controlled trial of duloxetine in the treatment of women with fibromyalgia with or without major depressive disorder. Pain 2005; 119: 5-15.

47. Arnold LM. Biology and therapy of fibromyalgia. New therapies in fibromyalgia. Arthritis Res Ther 2006; 8: 212-32.

48. Santandrea S, Montrone F, Sarzi-Puttini P, Boccassini L, Caruso I. A double-blind crossover study of two cyclobenzaprine regimens in primary fibromyalgia syndrome. J Int Med Res 1993; 21: 74-80. 
49. Tofferi JK, Jackson JL, O’Malley PG. Treatment of fibromyalgia with cyclobenzaprine: A meta-analysis. Arthritis Rheum 2004; 51: 9-13.

50. Torta R, Bovero A. L'intervento integrato fra psicoterapia breve ed antidepressivi nel dolore oncologico. Il Giornale di Psiconcologia, 2008, in press.

51. Benedetti F. What do you expect from this treatment? Changing our mind about clinical trials. Pain 2007; 128 : 193-4.

52. Colloca L, Benedetti F. Nocebo hyperalgesia: how anxiety is turned into pain. Curr Opin Anaesthesiol 2007; 20: 435-9.

53. Dworkin RH, Backonja M, Rowbotham MC, Allen RR, Argoff CR, Bennett GJ, et al. Advances in neuropathic pain: diagnosis, mechanisms, and treatment recommendations. Arch Neurol 2003; 60: 1524-34.

54. McQuay H, Carroll D, Jadad AR, Wiffen P, Moore A. Anticonvulsant drugs for management of pain: a systematic review. BMJ 1995; 311: 1047-52.

55. Abdi S, Lee DH, Chung JM. The anti-allodynic effects of amitriptyline, gabapentin, and lidocaine in a rat model of neuropathic pain. Anesth Analg 1998; 87: 1360-6.

56. Taylor CP, Gee NS, Su TZ, Kocsis JD, Welty DF, Brown JP, et al. A summary of mechanistic hypotheses of gabapentin pharmacology [review]. Epilepsy Res 1998; 29: 233-49.

57. Arnold LM, Goldenberg DL, Stanford SB, Lalonde JK, Sandhu HS, Keck PE Jr, et al. Gabapentin in the treatment of fibromyalgia: a randomized, double blind, placebo-controlled, multicenter trial. Arthritis Rheum 2007; 56: 1336-44.

58. Gee NS, Brown JP, Dissanayake VU, Offord J, Thurlow R, Woodruff GN. The novel anticonvulsant drug, gabapentin (neurontin), binds to the ${ }_{2}$ subunit of a calcium channel. J Biol Chem 1996; 271: 5768-76.

59. Fink K, Dooley DJ, Meder WP, Suman-Chauhan N, Duffy S, Clusmann $\mathrm{H}$, et al. Inhibition of neuronal $\mathrm{Ca}(2+)$ influx by gabapentin and pregabalin in the human neocortex. Neuropharmacology 2002; 42: 229-36.

60. Maneuf YP, Hughes J, McKnight AT. Gabapentin inhibits the substance P-facilitated $\mathrm{K}(+)$-evoked release of $\left[{ }^{(3)} \mathrm{H}\right]$ glutamate from rat caudal trigeminal nucleus slices. Pain 2001; 93: 191-6.

61. Crofford LJ, Rowbotham MC, Mease PJ, Russell IJ, Dworkin RH, Corbin AE, et al. Pregabalin for the treatment of fibromyalgia syndrome: results of a randomized, double blind, placebo-controlled trial. Arthritis Rheum 2005; 52: 1264-73.
62. Arnold LM, Crofford LJ, Martin SA, Young JP, Sharma U. The effect of anxiety and depression on improvements in pain in a randomized, controlled trial of pregabalin for treatment of fibromyalgia. Pain Med 2007; 8: 633-8.

63. Mease PJ, Russell IJ, Arnold LM, Florian H, Young JP Jr, Martin SA, Sharma U. A Randomized, Doubleblind, Placebo-Controlled, Phase III Trial of Pregabalin in the Treatment of Patients with Fibromyalgia. J Rheumatol 2008 Feb 15 [Epub ahead of print].

64. Färber L, Stratz TH, Brückle W, Späth M, Pongratz D, Lautenschläger J, et al. Short-term treatment of primary fibromyalgia with the 5-HT3-receptor antagonist tropisetron. Results of a randomized, double-blind, placebocontrolled multicenter trial in 418 patients. Int J Clin Pharmacol Res 2001; 21: 1-13.

65. Späth M, Stratz T, Färber L, Haus U, Pongratz D. Treatment of fibromyalgia with tropisetron-dose and efficacy correlations. Scand J Rheumatol (Suppl.) 2004; (119): 63-6.

66. Papadopoulos IA, Georgiou PE, Katsimbri PP, Drosos AA. Treatment of fibromyalgia with tropisetron, a 5HT3 serotonin antagonist: a pilot study. Clin Rheumatol 2000; 19: 6-8.

67. Koeppe C, Schneider C, Thieme K, Mense S, Stratz T, Müller W, Flor H. The influence of the 5-HT3 receptor antagonist tropisetron on pain in fibromyalgia: a functional magnetic resonance imaging pilot study. Scand J Rheumatol Suppl 2004; (119): 24-7.

68. Wood PB, Kablinger AS, Caldito GS. Open trial of pindolol in the treatment of fibromyalgia. Ann Pharmacother 2005; 39: 1812-6.

69. Jones KD, Deodhar P, Lorentzen A, Bennett RM, Deodhar AA. Growth hormone perturbations in fibromyalgia: a review. Semin Arthritis Rheum. 2007; 36: 357-79.

70. Sörensen J, Bengtsson A, Bäckman E, Henriksson KG, Bengtsson M. Pain analysis in patients with fibromyalgia. Effects of intravenous morphine, lidocaine, and ketamine. Scand J Rheumatol 1995; 24: 360-5.

71. Staud R. Are tender point injections beneficial: the role of tonic nociception in fibromyalgia. Curr Pharm Des 2006 12: 23-7.

72. Buskila D, Sarzi-Puttini P, Ablin JN. The genetics of fibromyalgia syndrome. Pharmacogenomics 2007; 8: 67-74.

73. Buskila D, Sarzi-Puttini P. Biology and therapy of fibromyalgia. Genetic aspects of fibromyalgia syndrome. Arthritis Res Ther 2006; 8: 218. 